\title{
Subcontracting and International Trade Policy
}

\author{
Wen-Jung Liang \\ Tamkang University \\ Ho-Chyuan Chen \\ National Kaohsiung First University of Science \& Technology \\ Mau-Shan Shi \\ Institute of Economics, Academia Sinica.
}

\begin{abstract}
This paper examines the optimal trade policies when international subcontracting occurs between two competing firms. It shows that if the strategic substitutes effect dominates the cost saving transfer effect, then the exporting country will impose a different policy on each export. In contrast, if the cost saving transfer effect dominates the strategic substitutes effect, then the exporting country will impose a tax policy on both exports. However, there has never existed an optimal policy to subsidize the export of both the subcontracted product and final product. Even though the exporting firm assumes away its export of the final good, to subsidize the export of the subcontracted good is not necessarily an optimal policy for the exporting country. For the importing country, if the price elasticity of demand is sufficiently small and the marketing cost of the final product is large enough, then it is optimal to set a negative tariff.
\end{abstract}

- JEL Classifications: F13, L13

- Key words: International subcontracting, Optimal trade policy, Nash bargaining

*Corresponding address: Wen-Jung Liang Department of Industrial Economics Tamkang University Tamsui, Taipei Hsien, Taiwan 25137 Tel: +886-2-2625-1863 Fax: +886-2-2622-7774 E-mail: wjliang@mail.tku.edu.tw

(C2003-Center for International Economics, Sejong Institution, All Rights Reserved. 


\section{Introduction}

In their prominent paper Spencer and Jones (1991) claim that it is optimal for an exporting country to impose either taxes or subsidies on both exports of its intermediate good and final good. This claim is modified in this paper when international subcontracting is taken into account.

Subcontracting is common in industries. Ikeda (1989) finds in the automobile industry that some 75 percent of the final product in Japan is produced by subcontractors, while the figure is about 50 percent in the U.S. and Europe. ${ }^{1}$ An extreme case in the American computer industry is Dell, which subcontracts all its production to overseas subcontracting suppliers. TSMC and UMC in Taiwan, due to a much lower production cost, have become the largest international subcontractors in the semiconductor foundry industry. ${ }^{2}$ Acer, Taiwan's largest PC maker, produces computers for IBM as well as Dell. However, it is also common that subcontractors sell their own brands to compete with consignors in the same market. Acer is an exact the case by selling its PCs with its own brand "Acer" to the U.S.

This paper examines the incentives for a strategic trade policy for two firms when subcontracting between them occurs. The firms first Cournot-compete in country 2 for the sales of the final good and then negotiate over a subcontract in which part of the production is shifted from the higher-cost to the lower-cost firm. The lower cost firm, denoted firm 1, produces at a constant marginal cost in country 1 and exports to country 2, whereas firm 2 in country 2 produces at an increasing marginal cost. Thus, part of firm 1's production (termed as the upstream good or the subcontracted good) is delivered to firm 2, and the other part (termed as the downstream good or the final good) is sold to country 2 under Cournot competition with firm 2. Firm 1 (country 1 ) is the exporting firm (country), while firm 2 (country 2) is the importing firm (country). Since market competition occurs before the subcontracting decision, the Cournot outcome is influenced by the anticipated payoffs and marginal production costs that arise from

\footnotetext{
${ }^{1}$ See Kamien et al. (1989).

${ }^{2}$ Taiwan is acknowledged as the largest subcontractor in many industries. Two kinds of subcontracting production, OEM and ODM, are commonly employed. OEM, denoted by Original Equipment Manufacturing, means that the prime contractor provides the design and the subcontracting producer supplies the manufacturing capacity. ODM, represented by Original Designer Manufacturing, is when the subcontracting producer provides both the design and capacity.
} 
subcontracting.

Three trade policies are considered. An export subsidy and an export tax is respectively applied by country 1 to exports of the downstream output and to exports of the subcontracted quantity. ${ }^{3}$ The downstream output from country 1 is also subject to an import tariff set by country 2 .

Subcontracting significantly alters the incentives for trade policy. With subcontracting it is possible that country 1 can gain from taxing the exports of the downstream good and subsidizing the exports of the subcontracted good or vice versa. On the other hand, in the absence of subcontracting, Spencer and Jones (1991) show that the exporting country gains by setting a tax or a subsidy on the exports of both the downstream and intermediate product. The policy of a subsidy to the export of one good and a tax on the other, in their paper, was not a possibility.

This setting whereby firms sign the subcontracting contract after going into the market competition, which is termed as ex post subcontracting hereafter, is proper and fits the reality. As Spiegel (1993) points out, when there occurs considerable uncertainty about either the demand for a downstream product or the marketing cost (which can be learned only when they actually set their downstream quantities), the firms may wish to postpone their subcontracting decisions ex post: ${ }^{4}$

"In fact, even when firms sign a subcontracting agreement before they compete in the market, they may wish to determine the actual subcontracted quantity only ex post. This seems to have been the case with the agreement between Mazda and Ford on Mazda's production of the Ford Probe. When the car was first introduced in March 1988, Ford could not satisfy the demand for the car, which presumably exceeded Ford's initial expectations (Los Angeles Times, May 19, 1988, sec. 4, p. 1). Moreover, Ford accumulated advance orders from dealers for 77,000 cars. This suggests that although the subcontracting agreement between the two firms was signed before any car was sold to consumers, the actual subcontracted quantity was set only after the quantity of the final good was determined by Ford in the market. (Spiegel 1993, p. 571, footnote 6)"

In comparison, our setting of ex post subcontracting leads to a departure from

\footnotetext{
${ }^{3}$ Collie (1997) argues that although the World Trade Organization prohibits export subsidies, many industrialized countries use export credits and export credit insurance to give their firms an advantage when exporting capital good to developing countries. This justifies our consideration of subsidy as a trade policy.

${ }^{4}$ See Spiegel (1993), p. 571, footnote 6.
} 
Spencer and Jones (1991). Even though the subcontracted product may be seen as a form of intermediate good to the consignor in a broad sense, a subcontracting quantity increase basically decreases the importing firm's total output of final good. However, a rise of the intermediate good in Spencer and Jones (1991) does increase the importing firm's output of the final good. The competition situation of two firms in the market thus changes. Moreover, through bargaining we endogenize the subcontracting price, while Spencer and Jones (1991) let the exporting firm choose the price of intermediate good.

Spencer and Jones (1991) prove that it is optimal for the exporting country to impose either taxes or subsidies on both exports of its intermediate good and final good. ${ }^{5}$ However, we show that if the subcontracting gain is greater (less) than the downstream loss when the consignor increases its downstream quantity, the exporting country tends to subsidize (tax) the subcontracted product and tax (subsidize) the downstream product. This implies that the exporting country will never have the same policy on both exports. Moreover, since through Nash bargaining the importing country shares the expenses of taxes or the benefit of subsidies on the subcontracting product, the exporting country has an incentive to tax the exports of both goods. Accordingly, we find that an optimal policy for the exporting country is to never subsidize the export of both products.

In contrast with the result in Spencer and Brander (1983), we also show a single product international competition with specific restrictions forecloses the exporting firm out of the downstream market. ${ }^{6}$ Our paper shows there exists a possibility to tax the exports of the subcontracted product for the exporting country. ${ }^{7}$ Spencer and Brander (1983) in contrast find that the definite optimal policy is to subsidize the exports to help the domestic firm capture a larger share

\footnotetext{
${ }^{5}$ Their paper also uses a three-stage model, in which the government sets the trade policy first on the export of the intermediate good as well as the final good, then the exporting firm chooses its price for the intermediate good, and then both firms Cournot-compete in the final good market. In their paper and ours, there should be no ambiguity about the exporting and importing country, because both papers assume the final good is only sold in one country, which is the one who also imports the intermediate good or the subcontracted-out product.

${ }^{6}$ Spencer and Brander (1983) assume that both firms, each in one country, export the final good and compete in a third country

${ }^{7}$ For the exporting country, the subcontracted product is now the single product

${ }^{8}$ For more discussions about related international trade issues, readers can also refer to Brander and Spencer (1981, 1984a, 1985), Holm (1997), and Spencer and Jones (1992).
} 
of the imperfectly competitive rent. ${ }^{8}$ On the other hand, when considering the optimal importing policy, we find that the optimal importing tariff is positive if a tariff increase causes the price to rise by less than the tariff, which resembles what Brander and Spencer (1984b) argue. ${ }^{9}$ Moreover, the optimal tariff becomes negative if the price elasticity of demand is sufficiently small and if the importing firm's downstream marketing cost is large enough.

The model is described in section 2. Section 3 specifies the comparative statics. Section 4 explores the optimal policy of an exporting country, while a case with an exporting firm having a very high marketing cost is shown in Section 5. The optimal policy of an importing country is considered in Section 6. Section 7 contains concluding remarks.

\section{The Model}

Assume that two firms, 1 and 2, are respectively located in an exporting country (country 1) and an importing country (country 2). These two firms, each respectively producing $x_{1}$ and $x_{2}$, compete only in the importing country for sales of the final good. This marketing stage will be referred to as the downstream market. However, one firm for the sake of cost savings may subcontract out part of its quantity to the other for production. We use $x_{s}$ to denote the subcontracted quantity from the importing firm to the exporting firm, and assume it to be determined through a Nash bargaining process. We will refer to the production stage and the subcontracting process as the upstream market.

In the downstream market, the price of importing country's downstream product is determined by the inverse demand function $p=a-b x$ where $x=x_{1}+x_{2}$ represents the aggregate downstream quantities. ${ }^{10}$ For $i=1,2$, with $m_{i}$ denoting the marginal marketing cost of firm $i$, its total marketing cost for its product in importing country is $m_{i} x_{i}$.

In the upstream process, firm $i$ 's production cost $C_{i}$ can be described as $C_{1}=c_{1} \cdot\left(x_{1}+x_{s}\right)$, and $C_{2}=C_{2}\left(x_{2}-x_{s}\right)=\beta\left(x_{2}-x_{s}\right)+(\gamma / 2)\left(x_{2}-x_{s}\right)^{2}$, where coefficients $c_{1}, \beta$, and $\gamma$ are constants and $C_{2}\left(x_{2}-x_{s}\right)$ is increasing and convex in $x_{2}-x_{s}$, which is the

\footnotetext{
${ }^{9}$ Brander and Spencer (1984b) assume one firm exports the final good, the single product, to the other country, where the other firm exists, and where the only market occurs.

${ }^{10}$ In order to derive a clearer result, we make the inverse demand function be a linear form.

${ }^{11}$ To derive a clearer result, importing firm's cost function is assumed to be a quadratic form.
} 
importing firm's real producing quantity. ${ }^{11}$ Denoting parameter $\alpha^{\circ} \cup[0,1]$ as measuring exporting firm's bargaining power, and $1-\alpha$ as importing firm's, we assume exporting firm and importing firm reach their agreement on the subcontracted quantity $x_{s}$ through a Nash bargaining process.

For studying subcontracting, in Spiegel (1993), he analyzes two variants of the model -- ex post subcontracting and ex ante subcontracting. The first variant sets downstream quantities first, and then signs the subcontracting agreement. ${ }^{12}$ In the second variant, the firms sign a subcontracting agreement before they compete in the downstream market. Spiegel claims:

"Accordingly, the competitive effects of contracts are often examined in the framework of two-stage models, in which contracts are set in the first stage and competition takes place in the second. This modeling approach, however, is appropriate in the context of horizontal subcontracting only to the extent that one believes that firms set the terms of their contracting agreements before they actually determine their downstream quantities. In many cases, however, this does not seem to be the case. For example, when there is considerable uncertainty about the demand for the final good or the cost of marketing, firms may prefer to postpone their decisions about subcontracts until they actually receive orders from downstream retailers. (Spiegel, 1993, p.571)"

Basically, our model follows the first variant of Spiegel's. In order to explore the issue of international trade, we add in a prior stage, concerning the international trade policy. Thus, a three-stage game is constructed. In prior stage, exporting country has imposed a specific subsidy $\sigma$ and a specific tax $v$ on exports of the downstream product and the subcontracted product respectively, while importing country has imposed a tariff $t$ on the imports of the downstream product. Both countries are assumed to commit to their postulated policies. In stage 1, exporting firm and importing firm engage in a Cournot quantity competition in importing country's downstream market. In stage 2 , the two firms sign a subcontracting agreement, according to which exporting firm will produce $x_{s}$ units of subcontracted quantities for the higher-cost rival importing firm, and in return will receive a transfer payment $T$.

Without loss of generality, we assume that the subcontracted product is

\footnotetext{
${ }^{12}$ Kamien et al. (1989) also develop a similar subcontracting game in which the downstream quantities are determined in the first stage while a subcontracting contract is signed in the second stage.

${ }^{13}$ In reality, many importers, such as automobile importers, are commonly utilizing this approach to reduce their tariff payments due to a much higher tariff on the product than that on the parts.
} 
partitioned into parts and exported in the form of intermediate goods. ${ }^{13}$ Consignors then assemble these intermediate goods with a comparatively small and negligible cost in our analysis. ${ }^{14}$ Therefore, the downstream product and the subcontracted product are distinguishable for different export trading policies.

\section{Comparative Statics}

Following backward induction, the analysis begins by considering the decisions in stage 2 -- the upstream stage. At this stage, given their downstream quantities and government policies, the two firms sign a subcontracting agreement, according to which exporting firm produces subcontracted quantity $x_{s}$ for importing firm. Since each firm's sales in the downstream market has been determined in stage 1, the Nash bargaining process works to split the maximizing joint cost savings (i.e., the minimizing joint upstream cost).

The subcontracting contract acts therefore to move some production from the higher marginal production cost firm to the lower one to save costs. Of course, the higher marginal production cost firm has to compensate the lower one with a transfer payment. The joint cost savings, denoted as $S^{r}$, takes the form as follows:

$$
S^{r}=\left[c_{1} x_{1}+C_{2}\left(x_{2}\right)\right]-\left[c_{1}\left(x_{1}+x_{s}\right)+C_{2}\left(x_{2}-x_{s}\right)+v x_{s}\right],
$$

which is just the joint cost difference between not having and having a subcontract. Deriving the first order condition of (1) with respect to $x_{s}$, the maximum joint cost savings occurs when each firm has an equal marginal production cost, i.e., when

$$
c_{1}+v=\beta+\gamma\left(x_{2}-x_{s}\right)
$$

Solving equation (2), we obtain the optimal subcontracted quantity as follows:

$$
x_{s}=x_{2}+(1 / \gamma)\left(\beta-c_{1}-v\right)
$$

Substituting (3) into (1), the maximum surplus of subcontracting is thus derived. Through the Nash bargaining solution, the exporting firm's bargaining power $\alpha$ indicates it will take a share $\alpha$ of both the benefit and the cost resulting from the enforcement of a subcontract. Therefore, it will be allotted $\alpha$ fraction of the total cost savings due to subcontracting, and is only willing to take $\alpha$ fraction of the

\footnotetext{
${ }^{14}$ Since consignor (importing firm) produces downstream product as well, the assembly takes place in the already-built capacity. It is reasonable to think this assembly cost as small and negligible. Also note that we assume exporting firm doesn't have already-built capacity in importing country to assemble parts. This will cause exporting firm a large cost if it exports parts rather than downstream final product.
} 
total extra trading cost. Clearly, the first part is the value of $\alpha\left[C_{2}\left(x_{2}\right)-C_{2}\left(x_{2}-\right.\right.$ $\left.\left.x_{s}\left(x_{2}, v\right)\right)\right]$. The second part, on the other hand, implies compensation from the importing firm equaling a $(1-\alpha)$ fraction of the total extra trading cost due to subcontracting [i.e., $(1-\alpha)\left(c_{1}+v\right) x_{s}\left(x_{2}, v\right)$ ] must be made to the exporting firm. We therefore obtain the transfer payment from the importing firm to exporting firm as the following equation:

$$
T=(1-\alpha)\left(c_{1}+v\right) x_{s}\left(x_{2}, v\right)+\alpha\left[C_{2}\left(x_{2}\right)-C_{2}\left(x_{2}-x_{s}\left(x_{2}, v\right)\right)\right]
$$

With this transfer payment, the profits of exporting firm and importing firm respectively turn out to be:

$$
\begin{gathered}
\pi^{1}=\left(p+\sigma-t-m_{1}\right) x_{1}-c_{1}\left(x_{1}+x_{s}\left(x_{2}, v\right)\right)-v x_{s}\left(x_{2}, v\right)+T \\
=\left(p+\sigma-t-m_{1}-c_{1}\right) x_{1}+\alpha\left\{\left[C_{2}\left(x_{2}\right)-C_{2}\left(x_{2}-x_{s}\left(x_{2}, v\right)\right)\right]-\left(c_{1}+v\right) x_{s}\left(x_{2}, v\right)\right\}, \\
\pi^{2}=\left(p-m_{2}\right) x_{2}-C_{2}\left(x_{2}-x_{s}\right)-T \\
=\left[\left(p-m_{2}\right) x_{2}-C_{2}\left(x_{2}\right)\right]+(1-\alpha)\left\{\left[C_{2}\left(x_{2}\right)-C_{2}\left(x_{2}-x_{s}\left(x_{2}, v\right)\right)\right]-\left(c_{1}+v\right) x_{s}\left(x_{2}, v\right)\right\} .
\end{gathered}
$$

The exporting firm's profit is the total revenue of the exporting downstream product minus its marketing cost, total upstream production cost, net exporting tax payment, and plus the transfer payment for the subcontracting production. As shown in the second equality of (5), the exporting firm's profit can be alternatively represented by the profit sum of exporting the downstream product and the subcontracting product. As for the importing firm, its profit is obtained by subtracting from its revenue the marketing cost, the upstream production cost, and the transfer payment. Alternatively, the importing firm's profit may be represented by the profit sum of the sale of the downstream product and the imports of the subcontracting product.

Anticipating the optimal subcontracted quantity in stage 2, each firm decides the downstream quantity in stage 1 to maximize its profit. We therefore obtain the first-order conditions as:

$$
\begin{gathered}
\pi_{1}^{1}=\left(p+\sigma-t-m_{1}-c_{1}\right)-b x_{1}=0, \\
\pi_{2}^{2}=\left(p-m_{2}\right)-b x_{2}-(1-\alpha)\left(c_{1}+v\right)-\alpha\left(\beta+\gamma x_{2}\right)=0
\end{gathered}
$$

The second-order conditions thus require that:

$$
\begin{gathered}
\pi_{11}^{1}=-2 b<0, \pi_{22}^{2}=-2 b-\alpha \gamma<0, \\
\text { and } H=3 b^{2}+2 b \alpha \gamma>0 .
\end{gathered}
$$


Using superscript $\mathrm{c}$ to denote the Cournot equilibrium value of the variables throughout the paper, we obtain the Cournot equilibrium outputs by (7) and (8) as follows:

$$
\begin{gathered}
x_{1}^{\mathrm{c}}=(1 / H)\left\{(2 b+\alpha \gamma)(\sigma-t)+b(1-\alpha) v+F_{1}\right\}, \text { and } \\
x_{2}^{\mathrm{c}}=(b / H)\left\{-(\sigma-t)-(1-\alpha) v+F_{2}\right\},
\end{gathered}
$$

where $F_{1}=a(b+\alpha \gamma)+(2 b+\alpha \gamma)\left(-m_{1}-c_{1}\right)+b\left[m_{2}+(1-\alpha) c_{1}+\alpha \beta\right]$, and

$$
F_{2}=a+\left(m_{1}+c_{1}\right)-2\left[m_{2}+(1-\alpha) c_{1}+\alpha \beta\right] \text {. }
$$

Substituting (10) into (3), we obtain the Cournot equilibrium subcontractedquantity $\mathrm{x}_{\mathrm{s}}^{\mathrm{c}}$ as:

$$
\begin{gathered}
x_{s}^{c}=(1 / \gamma H)\left\{-b \gamma(\sigma-t)-[b \gamma(1-\alpha)+H] v+F_{3}\right\}, \\
\text { where } F_{3}=b \gamma F_{2}+\left(B-c_{1}\right) H .
\end{gathered}
$$

Taking total differentials of (10) gives the comparative statics as follows:

$$
\begin{gathered}
x_{1 \sigma}^{c}=(2 b+\alpha \gamma) / H>0 \text { and } x_{2 \sigma}^{c}=-b / H<0, \\
x_{1 v}^{c}=b(1-\alpha) / H \geq 0 \text { and } x_{2 v}^{c}=-b(1-\alpha) / H \leq 0, \\
x_{1 t}^{c}=-(2 b+\alpha \gamma) / H<0 \text { and } x_{2 t}^{c}=b / H>0
\end{gathered}
$$

The comparative statics readily show that exporting country's downstream quantity increases while importing country's decreases when exporting country's export subsidy $\sigma$ rises, or when importing country's import tariff $t$ comes down. Moreover, if exporting country imposes a higher tax on the export of the subcontracted good, exporting firm will never decrease (while importing firm will never increase) its downstream quantity. ${ }^{15}$

From (11), we obtain:

$$
\begin{gathered}
x_{s \sigma}^{c}=x_{2 \sigma}<0, x_{s v}^{c}=x_{2 v}^{c}+(-1 / \gamma)<0, \\
\text { and } x_{s t}^{c}=x_{2 t}^{c}>0
\end{gathered}
$$

Intuitively, (15) indicates that the subcontracted quantity decreases when there is a rise in exporting country's export subsidy $\sigma$, export tax $v$, or a fall in importing country's import tariff $t$.

\footnotetext{
${ }^{15}$ Note that the higher tax on the export of the subcontracted product will not change each firm's downstream quantity, if exporting firm has all the bargaining power, i.e., if $\alpha=1$.
} 


\section{Optimal Export Policy of the Exporting Country}

Since final good $x$ is only sold in importing country, in prior stage, exporting country's welfare (denoted as $w^{1}$ ) will equal exporting firm's profit minus the net subsidies from the government, and thus can be expressed as follows by taking into account stage 1's Cournot equilibrium:

$$
w^{1}=\pi^{1}\left(x_{1}^{c}, x_{2}^{c}, x_{s}^{c}, \sigma, v, t\right)-\sigma x_{1}^{c}+v x_{s}^{c} .
$$

Before proceeding further, a definition of new notations is helpful. As we can observe from equation (10) and (11), term $x_{c}^{i}$, for $i=1,2, s$, can be completely expressed by a function of $(\sigma, v, t)$, which enables us to define $x_{i}^{c}=x_{i}^{c}(\sigma, v, t)$. Accordingly, the reduced form of $\pi^{1}$ and its derivative $\pi_{2}^{1}$ can be defined as $\pi^{1}=$ $\pi^{1}(\sigma, v, t)$ and $\pi_{2}^{1}=\pi_{2}^{1}(\sigma, v, t)$. Therefore, the expression of a function of $(0,0, t)$ is the result of the function of $(\sigma, v, t)$ measured at $\sigma=0$ and $v=0$. The rest may be deduced by analogy.

The objective of the exporting country's government is to choose an export policy to maximize the welfare. Taking a partial derivation of (16) with respect to $\sigma$ and $v$, we show in the Appendix the optimal levels of $\sigma$ and $v$ :

$$
\begin{gathered}
\sigma=\left(\frac{x_{2 \sigma}^{c}}{J}\right)\left\{A_{1} \pi_{2}^{1}(0,0, t)+A_{2}(1-\alpha) x_{s}^{c}(0,0, t)\right\}, \\
v=\left(\frac{1}{J}\right)\left\{A_{3} \pi_{2}^{1}(0,0, t)-\mathrm{w}_{\sigma \sigma}^{1}(1-\alpha) x_{s}^{c}(0,0, t)\right\}, \\
\text { where } A_{1}=(1 / \gamma)-(1-\alpha) x_{s v}^{c}>0, \\
A_{2}=(1 / H) b(1-\alpha)(2 b+\alpha \gamma)>0, \\
A_{3}=-(1 / H)^{2}(1-\alpha) b \alpha \gamma<0, \text { and } \\
\pi_{2}^{1}(0,0, t)=\alpha \gamma x_{s}^{c}(0,0, t)-b x_{1}^{c}(0,0, t) .
\end{gathered}
$$

Note that, as shown in Appendix, term $\pi_{2}^{1}=\alpha\left[C_{2 x}\left(x_{2}^{c}\right)-C_{2 x}\left(x_{2}^{c}-\right.\right.$ $\left.\left.x_{s}^{c}\right)\right]+x_{1}^{c} p^{\prime}=\alpha \gamma x_{s}^{c}-b x_{1}^{c}$ indicates that, holding $x_{1}$ fixed, an increase in the importing firm's downstream quantity gives the exporting firm a subcontracting profit gain $\alpha\left[C_{2 x}\left(x_{2}^{c}\right)-C_{2 x}\left(x_{2}^{c}-x_{s}^{c}\right)\right]$, and a downstream profit loss $x_{1}^{c} p^{\prime}$ due to the fall in the price of the downstream product. In other words, term $\pi_{2}{ }^{1}$ can be referred to as the sum of the subcontracting gain and downstream loss due to the importing firm's downstream quantity increase.

Since $J>0, H>0,1-\alpha \geq 0$, and $w^{1}{ }_{\sigma \sigma}<0, x_{s v}^{c}<0$, and $x_{2 \sigma}^{c}<0$, equation (17) readily 
shows that a negative subsidy policy on the export of the downstream product will be employed by the exporting country if $\pi_{2}^{1}(0,0, t)>\left\{-A_{2}(1-\alpha) x_{s}^{c}(0,0, t)\right\} / A_{1}$, while a positive subsidy policy occurs if $\pi_{2}{ }^{1}(0,0, t)<\left\{-A_{2}(1-\alpha) x_{s}^{c}(0,0, t)\right\} / A_{1}<0$. On the other hand, equation (18) tells that a negative tax policy on the export of the subcontracted product will be employed if $\pi_{2}{ }^{1}(0,0, t)>\left\{w_{\sigma \sigma}^{1}(1-\alpha) x_{s}^{c}(0,0, t)\right\} / A_{3}$ $>0$, while a positive tax policy occurs if $\pi_{2}^{1}(0,0, t)<\left\{w^{1}{ }_{\sigma \sigma}(1-\alpha) x_{s}^{c}(0,0, t)\right\} / A_{3}$.

As shown above, a positive $\pi_{2}{ }^{1}(0,0, t)$ implies that exporting firm earns a higher subcontracting gain than the downstream loss when importing firm increases its downstream quantity. This gives the exporting country an incentive to tax the export of the downstream product and to subsidize the export of the subcontracted product, because a rise in the tax (subsidy) on the export of the downstream (subcontracted) product leads to an increase in importing firm's downstream quantity. Conversely, the exporting country tends to subsidize the export of the downstream product and tax the export of the subcontracted product when $\pi_{2}{ }^{1}(0$, $0, t)$ is negative. This result, due to the exporting country switching resources to a more profitable one, will be hereafter referred to as the strategic substitutes effect. It is shown on the first term in the brace of the right-hand side of (17) and (18).

There also exists the cost saving transfer effect, which appears on the second term in the brace of the right-hand side of (17) and (18). Through Nash bargaining, part of exporting firm's subcontracting taxes $(1-\alpha) v x^{\mathrm{s}}$ is transferred to importing firm. If the exporting country imposes a tax on the export of the subcontracted product, then the importing country will be forced to share this cost. Therefore, the exporting country will have an incentive to impose a tax rather than a subsidy on the export of the subcontracted product. On the other hand, if the exporting country sets a subsidy on the downstream product, the subcontracted quantity will fall, decreasing the net tax revenues $(1-\alpha) v x^{s}$ as well as the welfare of the exporting country. This gives incentive to the exporting country to tax the export of its downstream product. Consequently, the cost saving transfer effect tends to drive the exporting country to tax both of the products.

The combination of the two above effects determines the government's optimal policy on its exports. If the strategic substitutes effect dominates the cost saving transfer effect, then the exporting country will impose a different trade policy on each export. That is, if $\pi_{2}^{1}(0,0, t)>\left\{w_{\sigma \sigma}^{1}(1-\alpha) x_{s}^{c}(0,0, t)\right\} / A_{3}>0$, then the optimal policy is to tax the downstream product and subsidize the subcontracted product, while it is optimal to set a subsidy on the downstream product and tax the subcontracted product if $\pi_{2}{ }^{1}(0,0, t)<\left\{-A_{2}(1-\alpha) x_{s}^{c}(0,0, t)\right\} / A_{1}<0$. If the cost saving 
transfer effect dominates the strategic substitutes effect, then the exporting country will impose a tax policy on both exports. This occurs when $\left\{-A_{2}(1-\alpha) x_{s}^{c}(0,0, t)\right\} /$ $\left.A_{1}<\pi_{2}{ }^{1}(0,0, t)<\left\{w^{1}{ }_{\sigma \sigma}(1-\alpha) x^{c}{ }_{s}(0,0, t)\right\} / A_{3}\right\}$. However, an optimal policy for subsidizing both exports does not exist.

Proposition 1. If the strategic substitutes effect dominates the cost saving transfer effect, then the exporting country would impose a different trade policy on each export. In contrast, if the cost saving transfer effect dominates the strategic substitutes effect, then the exporting country would impose a tax policy on both exports. However, there will never exist an optimal policy to subsidize the export of both the subcontracted product and final product.

The first part and the third part of Proposition 1 are in sharp contrast to Spencer and Jones (1991). In their paper they show that it is optimal for exporting country to tax the export of both products if the difference in profit margins from the export of the intermediate good and final good is positive. On the contrary, it is optimal to subsidize the exports of both products if the difference in profit margins is negative. In our paper we find that the government would impose a different trade policy on each export when the absolute value of $\pi_{2}{ }^{1}(0,0, t)$ is sufficiently large, no matter what the sign of $\pi_{2}^{1}(0,0, t)$ is. More surprisingly, an optimal policy involving a subsidy on both products is not achievable.

\section{An Exporting Firm with a High Marketing Cost}

This section applies our model to a special case - Taiwan's high-tech industry. As we see, under OEM production Taiwan has become the world's largest manufacturer of PCs, with most of these computers sold to the U.S. However, only one brand, Acer, is created and is exported as a downstream product. Creation of a new brand involves the cost of advertising, sales network, marketing, etc., which creates barriers for entry. We use the term marketing costs to include all these kinds of costs. Obviously, when the downstream marketing cost is too high, it will discourage exporting firm's export of the downstream product, and therefore it will switch to the exports of subcontracted product.

We assume in this section that exporting country's downstream marketing cost $m_{1}$ is so expensive that the first-order condition in (7) is always less than zero. This results in exporting firm's exit from the downstream market and entry into 
producing the subcontracted product only. Under zero export of the downstream product, the tax on exports of the subcontracted product must satisfy the following welfare-maximizing condition: ${ }^{16}$

$$
\begin{gathered}
v=\left(\frac{-1}{w_{v v}^{1}}\right)\left\{x_{2 v}^{c} \pi_{2}^{1 m}(0, t)+(1-\alpha) x_{s}^{c}(0, t)\right\}, \\
\text { where } \pi_{2}^{1 m}(0, t)=\alpha \gamma x_{s}^{c}(0, t) \geq 0 .
\end{gathered}
$$

Here we use $\pi_{2}^{1 m}(v, t)$ to denote $\pi_{2}^{1}$ when the export of the downstream product is definitely zero. Accordingly, $\pi_{2}^{1 m}(0, t)$ represents the exporting firm's subcontracting profit gain due to an increase in the importing firm's downstream quantity when $x_{1}$ and $v$ equal zero. Note that variable $\sigma$ vanishes in this section due to $x_{1}=0$.

Comparing $\pi_{2}^{1 m}(0, t)$ to $\pi_{2}^{1}(\sigma, v, t)$, one can find that the downstream profit loss in $\pi_{2}{ }^{1}(\sigma, v, t)$ disappears because of zero export of the downstream product of the exporting firm. Since $w_{v v}^{1}<0, x_{2 v} \leq 0, \pi_{2}^{1 m}(0, t) \geq 0$, and $0 \leq \alpha \leq 1$, the sign of $v$ will depend on the magnitude of $\pi_{2}^{1 m}(0, t)$. The optimal tax is $v<0$ if $\pi_{2}^{1 m}(0, t)>[-(1-$ $\left.\alpha) x_{s}^{c}(0, t) / x_{2 v}^{c}\right]>0$, otherwise $v \geq 0$. As discussed above, $\pi_{2}^{1 m}(0, t)>0$ gives the government of the exporting country an incentive to subsidize the export of the subcontracted product by the strategic substitutes effect. A rise in the subsidy increases the export of the subcontracted product as well as the subsidies paid by the government, which is a leakage of welfare. Moreover, the cost saving transfer effect will move some benefit from a subsidy to the importing country, and dampen the increase in the exporting country's welfare. Therefore, in order for the exporting government to subsidize the export of the contracted product, the subcontracting profit gain must be large enough. That is, $\pi_{2}^{1 m}(0, t)$ must be larger than $-(1-\alpha) x_{s}^{c}(0, t) / x_{2 v}^{c}$ in mathematics.

Proposition 2. If it is too costly for exporting firm to produce the downstream product, then it is optimal for exporting country to subsidize the export of the subcontracted product when $\pi_{2}^{1 m}(0, t)>-(1-\alpha) x_{s}^{c}(0, t) / x_{2 v}^{c}>0$. Otherwise, a tax on the export of the subcontracted product becomes optimal.

This above result is different from that derived in Spencer and Brander (1983), who argue that the optimal policy for the exporting country is to subsidize the

\footnotetext{
${ }^{16}$ This can be derived by imposing $\sigma=0$ and substituting the Cournot equilibrium value of $x_{1}^{c}$ and $x_{s}^{c}$ to equation(A5).
} 
single exporting product when the market is imperfectly competitive. We show by Proposition 2 that when the single exporting product is a subcontracting good, a tax or a subsidy could be an optimal trade policy for the exporting country, depending on the magnitude of its subcontracting profit gain. This arises from the fact that in our paper the exporting country's incentive to use a tax policy rises, because part of exporting firm's tax burden on the export of the subcontracting product has been transferred to importing firm.

\section{Optimal Import Policy of the Importing Country}

As argued by Brander and Spencer $(1984,1985)$, the importing country has an incentive to set a tariff or a subsidy on the import of the imperfectly competitive good to extract some of the exporting firm's rent. However, when we take into account international subcontracting, the incentive might change. This investigation has not been studied yet in the literature, and is our focus of in this section.

Given the exporting country's policy (i.e., $\sigma$ and $v$ ), we are now ready to explore the importing country's reactions. We here define that the importing country's welfare $w^{2}$ equals its consumer surplus plus the importing firm's profits as well as the tariff revenue. Hence, we have:

$$
w^{2}=u\left(x^{c}\right)-p x^{c}+\pi^{2}\left(x_{1}^{c}, x_{2}^{c}, x_{\mathrm{s}}^{c}, v\right)+t x_{1}^{c}
$$

where $u\left(x^{c}\right)$ denotes the utility function and $x_{i}^{c}=x_{i}^{c}(\sigma, v, t)$ for $i=1,2, s .{ }^{17}$

Maximizing (20) with respect to $t$, we solve for the optimal level of $t$ in the Appendix as follows:

$$
\mathrm{t}=\left(\frac{-1}{w_{t t}^{2}}\right)\left\{x_{1}^{c}(\sigma, v, 0)\left(1-p_{\mathrm{t}}\right)+\left(p(\sigma, v, 0)-M C_{2}\right) x_{2 t}^{c}\right\}
$$

In fact, equation (21) is similar to the one derived in Brander and Spencer (1984) except for the content of $M C_{2}$, which is the importing firm's marginal cost for producing the downstream product. Since $w_{t t}^{2}<0, x_{2 t}^{c}>0, p-M C_{2} \geq 0$, and the sign of $1-p_{t}$ is indeterminate, the sign of the optimal tariff $t$ remains ambiguous. However, if the rate of change of the consumer price with respect to the tariff is less than one, i.e., if $p_{t}<1$, then we observe that the optimal tariff is positive, as the

\footnotetext{
${ }^{17}$ The utility has to exhibit a quadratic form because we have defined the inverse demand function as a linear equation.
} 
traditional viewpoint shows. ${ }^{18}$

By (8), we know that $p-M C_{2}=b x_{2}^{c}$, which can help us to rewrite (21):

$$
\mathrm{t}=\left(\frac{-1}{w_{t t}^{2}}\right)\left\{x_{1}^{c}(\sigma, v, 0)\left(1-p_{\mathrm{t}}\right)+b x_{2}^{c}(\sigma, v, 0) x_{2 t}^{c}\right\}
$$

If the price elasticity of demand is sufficiently small, then the value of the term $\mathrm{b}$ tends to be large, causing $1-p_{t}<0$ since $x_{t}^{c}=x_{1 t}^{c}+x_{2 \mathrm{t}}^{c}<0$. Together with the condition that exporting firm's downstream quantity relative to importing firm's downstream quantity (i.e., $x_{1}^{c} / x_{2}^{c}$ ) is sufficiently large (which can be derived when importing firm's downstream marketing cost $m_{2}$ is large enough), the optimal tariff for importing country is more likely to be negative. This happens because a rise in the import tariff will increase the price more if the price elasticity of demand is smaller. The consumer surplus thus drastically decreases, causing a big welfare loss. Even though the price increase also increases importing firm's profit, and could increase importing country's welfare, this effect is still dominated if importing firm's downstream quantity is small. Consequently, a rise in the import tariff will lower importing country's welfare, implying that subsidizing the import good will be an optimal policy. Hence, we can summarize the results in the following proposition:

Proposition 3. For importing country, the optimal import tariff is positive if the consumer price change rate with respect to the tariff is less than one. When the price elasticity of demand is sufficiently small, the optimal tariff becomes negative if importing firm's downstream marketing cost $\mathrm{m}^{2}$ is large enough.

\section{Concluding Remarks}

Taking into account the issue of international subcontracting, this paper has examined the optimal export policy for an exporting country, and the optimal import tariff policy for an importing country. Several striking results are found. Firstly, we show that if the strategic substitutes effect dominates the cost saving transfer effect, then the exporting country will impose a different trade policy on each of its exports. In contrast, if the cost saving transfer effect dominates the strategic substitutes effect, then the exporting country will impose a tax policy on

${ }^{18}$ The result can also be found in Brander and Spencer (1984a, 1984b, and 1985). 
both of its exports. However, there will never exist an optimal policy to subsidize the export of both the subcontracted product and the final product.

Secondly, we find that even in a single product market caused by an exporting firm's high marketing cost, there still exists a possibility for the exporting country to tax its exports. Thirdly, the importing country sets a negative tariff, if the price elasticity of demand is sufficiently small and the importing firm's downstream marketing cost is large enough.

Along these lines, there are some straightforward extensions. Firstly, one may introduce a noncooperative game in the subcontracting stage by considering two polar cases. In the first case, the prime contractor acts as a Stackelberg leader. He determines the quantity to be subcontracted and the price to be paid to maximize his own profit subject to the subcontractor's opportunity cost. In the second case, the subcontractor is the Stackelberg leader in the subcontracting stage. Secondly, one may study the cases of cooperative and noncooperative games, in which the subcontracted quantity is determined before setting the downstream quantity.

\section{Acknowkedgement}

The support of the national science council, Taiwan, ROC, is gratefully acknowledged. The authors are indebeted to the referee for his thonough, insightful, and stimulating comments on our paper.

Received 18 January 2002, Accepted 18 June 2002

\section{References}

Brander, J.A., and B.J. Spencer, 1984b, "Tariff Protection and Imperfect Competition,” in Henry Kierzkowski, ed., Monopolistic Competition and International Trade (Oxford University Press, Oxford).

Brander, J.A., and B.J. Spencer, 1985, "Export Subsidies and International Market Share Rivalry," Journal of International Economics 18, 83-100.

Bulow, J.I., Geanakoplos, J.D., and P.D., Klemperer, 1985, "Multimarket Oligopoly: Strategic Substitutes and Complements," Journal of Political Economy 93, 488-511.

Collie, D.R., 1997, "Bilateralism Is Good: Trade Blocs and Strategic Export Subsidies," Oxford Economic Papers 49, 504-520.

Holm, P., 1997, "Vertical Integrated Oligopoly and International Trade Policy," Canadian Journal of Economics 30, 194-207. 
Ikeda, M., 1989, “A Comparative Study of International Subcontracting System.” In K.

Shibagaki, M. Trevor, and T. Abo, eds., Japanese and European Management: Their International Adaptability. Tokyo: University of Tokyo Press.

Kamien, M.I., L. Li, and D. Samet, 1989, "Bertrand Competition with Subcontracting," RAND Journal of Economics 20:4, 553-567.

Spencer, B.J., and J.A. Brander, 1983, "International R\&D Rivalry and Industrial Strategy," Review of Economics Studies 50:4, 707-722.

Spencer, B.J., and R.W. Jones, 1991, "Vertical Foreclosure and International Trade

Policy," Review of Economics Studies 58:1, 153-170.

Spencer, B.J., and R.W. Jones, 1992, "Trade and Protection in Vertically Related

Markets," Journal of International Economics 32, 31-55.

Spiegel, Y., 1993, "Horizontal Subcontracting," RAND Journal of Economics 24:4, 570590.

\section{Appendix}

Optimal policy of the exporting country

Taking a partial derivation of (16) with respect to $\sigma$ and $v$, we obtain the firstorder conditions as follows:

$$
\begin{gathered}
w_{\sigma}^{1}=\pi_{1}^{1} x_{1 \sigma}^{\mathrm{c}}+\pi_{2}^{1} x_{2 \sigma}^{\mathrm{c}}+\pi_{3}^{1} x_{\sigma}^{1}-x_{1}^{\mathrm{c}}-\sigma x_{1 \sigma}^{c}+v x_{\mathrm{s} \sigma}^{c}=0 \\
w_{v}^{1}=\pi_{1}^{1} x_{1 v}^{c}+\pi_{2}^{1} x_{2 v}^{\mathrm{c}}+\pi_{3}^{1} x_{s v}^{c}+\pi_{v}^{1}-\sigma x_{1 v}^{\mathrm{c}}+x_{s}^{c}+v x_{\mathrm{s} v}^{c}=0
\end{gathered}
$$

By equation (7), we obtain $\pi_{1}^{1}=0$. From (5), we can derive $\pi_{3}^{1}=\alpha[-$ $\left.\left(c_{1}+v\right)+\beta+\gamma\left(x_{2}^{c}-x_{s}^{c}\right)\right]$ and $\pi_{2}^{1}=\alpha\left[C_{2 x}\left(x_{2}^{c}\right)-C_{2 x}\left(x_{2}^{c}-x_{s}^{c}\right)\right]+x_{1}^{c} \mathrm{p}^{\prime}=\alpha \gamma x_{s}^{c}-b x_{1}^{c}$, where $C_{2 x}\left(x_{2}^{c}-x_{s}^{c}\right)=\beta+\gamma\left(x_{2}^{c}-x_{s}^{c}\right)$ is the partial derivative of $C_{2}\left(x_{2}^{c}-x_{s}^{c}\right)$. However, through (2), we know that $\pi_{3}^{1}$ will equal zero under the first-order condition. Also note that, $\pi_{\sigma}^{1}=x_{1}^{c}$ and $\pi_{v}^{1}=-\alpha x_{s}^{c}$ by equation (16).

Through a careful arrangement of equations (10)-(15), the Cournot equilibrium $x_{1}^{c}$ and $x_{s}^{c}$ can be regrouped and expressed as the following results:

$$
\begin{gathered}
x_{1}^{c} \equiv x_{1}^{c}(\sigma, v, t)=x_{1 \sigma}^{c} \sigma+x_{1 v}^{c} v+x_{1}^{c}(0,0, t), \text { and } \\
x_{s}^{c} \equiv x_{s}^{c}(\sigma, v, t,)=x_{s \sigma}^{c} \sigma+x_{s v}^{c} v+x_{s}^{c}(0,0, t), \\
\text { where } x^{c}{ }_{1}(0,0, t)=F_{1} / H \geq 0, \text { and } \\
x_{s}^{c}(0,0, t)=F_{3} /(\gamma H) \geq 0 .
\end{gathered}
$$

Again, note that $x_{1}^{c}(0,0, t)$ and $x_{s}^{c}(0,0, t)$ are the measuring of $x_{1}^{c}(\sigma, v, t)$ and $x_{s}^{c}(\sigma$, $v, t)$ at $\sigma=v=0$, respectively.

Substituting (A3) into $\pi_{2}^{1}$, we can now derive the following relationship: 
$\pi_{2}^{1} \equiv \pi_{2}^{1}(\sigma, v, t)=\left(\alpha \gamma x_{s \sigma}^{c}-b x_{1 \sigma}^{c}\right) \sigma+\left(\alpha \gamma x_{s v}^{c}-b x_{1 v}^{c}\right) v+\pi_{2}^{1}(0,0, t)$,

where $\pi_{2}^{1}(0,0, t)=\alpha \gamma x_{s}^{c}(0,0, t)-b x_{1}^{c}(0,0, t)$.

Therefore, (A1) and (A2) can be reduced to:

$$
\begin{gathered}
w_{\sigma}^{1}=\pi_{2}^{1} x_{2 \sigma}^{c}-\sigma x_{1 \sigma}^{c}+v x_{s \sigma}^{c}=0 \\
w_{v}^{1}=\pi_{2}^{1} x_{2}^{c}-\sigma x_{1 v}^{c}+v x_{s}^{c}+(1-\alpha) x_{s}^{c}=0
\end{gathered}
$$

The second-order conditions of (A4) and (A5) can be shown to be well-defined:

$$
\begin{gathered}
w_{\sigma \sigma}^{1}=-x_{1 \sigma}^{c}+B_{1} x_{2 \sigma}^{c}<0, \\
\mathrm{w}_{v v}^{1}=x_{s v}^{c}+B_{2} x_{2 v}^{c}+(1-\alpha) x_{s \sigma}^{c}<0, \\
\text { and } J=w_{v v}^{1} w_{\sigma \sigma}^{1}-w_{\sigma v}^{1} w_{v \sigma}^{1}>0,
\end{gathered}
$$

where $\mathrm{B}_{1}=\alpha \gamma x_{s \sigma}^{c}-b x_{1 \sigma}^{c}=(-b / H)(2 b+2 \alpha \gamma)<0$, and

$$
B_{2}=\alpha \gamma x_{s v}^{c}-b x_{1 v}^{c}=-[b(1-\alpha) / H](b+\alpha \gamma)-\alpha<0
$$

To obtain the optimal levels of $\sigma$ and $v$, substitute $\pi_{2}^{1}$ into (A4) and (A5), and rearrange the results. We then can obtain the optimal levels as the form as shown in equations (17) and (18).

Optimal policy of the importing country

Maximizing $w^{2}$ with respect to $t$ given $\sigma$ and $v$ yields the first-order condition as:

$$
\begin{gathered}
w_{t}^{2}=u_{x} x_{t}^{c}-p x_{t}-x^{c} p_{t}+\pi_{1}^{2} x_{1 t}^{c}+\pi_{2}^{2} x_{s t}^{c}+x_{1}^{c}+t x_{1 t}^{c}=0 \\
\text { where } u_{x}=p, \\
\pi_{2}^{2}=x_{2}^{c} p^{\prime} \\
\pi_{2}^{2}=p+x_{2}^{c} p^{\prime}-M C_{2}, \\
M C_{2}=m_{2}+\alpha\left(\beta+\gamma x_{2}^{c}\right)+(1-\alpha)\left(c_{1}+v\right), \text { and } \\
\pi_{3}^{2}=(1-\alpha)\left[-\left(c_{1}+v\right)+\beta+\gamma\left(x_{2}^{c}-x_{s}^{c}\right)\right] .
\end{gathered}
$$

We know that $\pi_{2}^{2}=0$ by the first-order condition, and $\pi_{3}^{2}=0$ by (2). Notice also that $M C_{2}>0$ is the importing firm's marginal cost for producing the downstream product. Therefore, equation (A6) can be reduced to:

$$
\begin{gathered}
x_{1}^{c}\left(1-p_{t}\right)+\left(p-M C_{2}\right) x_{2 t}^{c}+t x_{1 t}^{c}=0, \\
\text { where } p_{t}=p^{\prime} x_{t}^{c} .
\end{gathered}
$$

We can also show a well-defined second-order condition as the following: 


$$
\begin{gathered}
w_{t t}^{2}=x_{1 t}^{c}+x_{1 t}^{c}\left(1-p_{t}\right)+\left(p_{t}-M C_{2 t}\right) x_{2 t}^{c}<0, \\
\text { where } M C_{2 t}=\alpha \gamma x_{2 t}^{c}
\end{gathered}
$$

Substituting (A.3) into (A.7), we can thus solve for the optimal level of $t$ as shown in equation (21). 